\title{
Interactive comment on "Large impact of tiny model domain shifts for the Pentecost 2014 MCS over Germany" by Christian Barthlott and Andrew I. Barrett
}

Christian Barthlott and Andrew I. Barrett

christian.barthlott@kit.edu

Received and published: 26 November 2019

The comment was uploaded in the form of a supplement:

http://www.weather-clim-dynam-discuss.net/wcd-2019-5/wcd-2019-5-AC2-

supplement.pdf

Interactive comment on Weather Clim. Dynam. Discuss., https://doi.org/10.5194/wcd-2019-5, 2019. 